\title{
Hematolojik kanser tanısıyla yoğun bakım ünitesinde takip edilen hastaların klinik özelliklerinin ve sonuçlarının değerlendirilmesi: tek merkez deneyimi
}

Evaluation of clinical features and results of patients followed up in the intensive care unit with the diagnosis of hematological cancer: a single center experience

İsmail Hakkı Akbudak

Öz

Giriş: Hematolojik kanser (HK) tanısı alan hastaların takip ve tedavisi sırasında sıklıkla yoğun bakım ihtiyacı olmaktadır. Bu çalışma ile yoğun bakım ünitesinde (YBÜ) takip edilen HK tanısı almış hastaların, klinik özellikleri ve takip sonuçlarının değerlendirilmesi amaçlanmıştır.

Gereç ve yöntem: Bu çalışmada, Şubat 2019 ile Mart 2020 tarihleri arasında yoğun bakım takibi gerektiren 77 erişkin hastanın kayıtları geriye dönük olarak incelenmiştir. Bulgular: Çalışmaya alınan, $38(\% 50,6)$ hasta nötropenikti ve YBÜ'ne yatış sırasında 67 hastada $(\% 87)$ enfeksiyon vardı. $35(\% 45,5)$ hastaya akut miyeloid lösemi tanısı konmuştu. $56(\% 72,7)$ hastaya yatışta mekanik ventilasyon uygulanmıştı. İzlemde $32(\% 41,6)$ hastada YBÜ enfeksiyonu, $24(\% 31,2)$ hastada bakteriyemi gelişmiş olup en sık saptanan patojenler; gramnegatif basillerden Klebsiella pneumonia $(n=11, \% 14,3)$ ve fermentasyon yapmayan bakterilerdi $(n=13$, $\% 16,6)$. Genel YBÜ sağ kalım oranı \%32,5 $(n=25)$ idi. Tek değişkenli analizde mortaliteyi etkilediği ön görülen değişkenler; APACHE II skoru $\geq 25(p<0,001)$, kanser tedavisine direnç veya relaps $(p=0,015)$, yatışta septik şok $(p<0,001)$, invaziv mekanik ventilasyon intiyacı $(p<0,001)$ ve hastane enfeksiyon varlığı $(p=0,006)$ istatistiksel olarak anlamlı risk faktörleri olarak saptandı. Bu değişkenler ile kurulan çok değişkenli model sonucunda ise APACHE II skorunun mortalite için anlamlı bir tahmin edici olduğu görüldü (ROC:0,884).

Sonuç: APACHE II skoru $\geq 25$ ve septik şok önemli kötü prognoz kriterleridir. Yoğun bakım ihtiyacı olan HK hastalarının takip ve tedavisinde belirlenecek protokoller, destekleyici tedaviler ve hastane enfeksiyonlarının önlenmesi ile tedavi başarısının ve yaşam süresinin uzatılması sağlanabilir.

Anahtar kelimeler: Yoğun bakım ünitesi, hematolojik kanser, enfeksiyon.

Akbudak IH. Hematolojik kanser tanısıyla yoğun bakım ünitesinde takip edilen hastaların klinik özelliklerinin ve sonuçlarının değerlendirilmesi: tek merkez deneyimi. Pam Tıp Derg 2021;14:684-690.

\begin{abstract}
Introduction: Patients diagnosed with hematological cancer $(\mathrm{HC})$ often need intensive care during their followup and treatment. In this study, it was aimed to evaluate the clinical characteristics and follow-up results of patients diagnosed with $\mathrm{HC}$ who were followed up in the intensive care unit (ICU).

Materials and methods: In this study, the records of 77 adult patients requiring intensive care follow-up between February 2019 and March 2020 were retrospectively examined.

Results: Thirty-eight $(50.6 \%)$ patients included in the study were neutropenic and 67 patients (87\%) had infection during admission to the ICU. Acute myeloid leukemia was diagnosed in $35(45.5 \%)$ patients. Mechanical ventilation was applied to $56(72.7 \%)$ patients on admission. In the follow-up, 32 (41.6\%) patients developed ICU infection, $24(31.2 \%)$ patients developed bacteremia. The most common pathogens were; Klebsiella pneumonia $(n=11,14.3 \%)$ and non-fermentation bacteria $(n=13,16.6 \%)$ were gram-negative bacilli. Overall ICU survival rate was $32.5 \%(n=25)$. Variables predicted to affect mortality in univariate analysis; APACHE II score $\geq 25$ $(p<0.001)$, resistance to cancer treatment or relapse $(p=0.015)$, septic shock at hospitalization $(p<0.001)$, need for invasive mechanical ventilation $(p<0.001)$ and presence of hospital infection $(p=0.006)$ were statistically were found to be significant risk factors. As a result of the multivariate model established with these variables, it was seen that the APACHE II score was a significant predictor for mortality (ROC:0.884).

Conclusion: APACHE II score 25 and septic shock are important poor prognosis criteria. Successful treatment and long survival can be achieved by the protocols to be determined in the follow-up and treatment of HC patients in need of intensive care, supportive treatments and prevention of nosocomial infections.
\end{abstract}

Key words: Intensive care unit, hematological cancer, infection.

Akbudak $\mathrm{IH}$. Evaluation of clinical features and results of patients followed up in the intensive care unit with the diagnosis of hematological cancer: a single center experience. Pam Med J 2021;14:684-690.

İsmail Hakkı Akbudak, Dr. Öğr. Üye. Pamukkale Üniversitesi Tıp Fakültesi, İç Hastalıkları Anabilim Dalı, Yoğun Bakım Bilim Dalı, Denizli, Türkiye, e-posta: ishakbudak@gmail.com (https://orcid.org/0000-0002-3716-9243) (Sorumlu Yazar) 


\section{Giriş}

Tüm Dünya'da ve ülkemizde Hematolojik kanser (HK) tanısı alan hastaların sayısı artmakla birlikte son dönem geliştirilen tanı, antineoplastik tedaviler ve destekleyici tedaviler sayesinde, bu hastaların tedavi başarısı artmakta ve yaşam süreleri uzamaktadır. Ancak, HK hastalarının hastalık sürecinde ve tedavi komplikasyonları nedeniyle sıklıkla yoğun bakım ünitesinde takip ve tedavi gerekliliği ortaya çıkmaktadır. Literatürde bu hastaların, mortalite oranları \%46-90 aralığında oldukça yüksek olarak bildirilmektedir [1-3]. Daha önce yapılan çalışmalarda yoğum bakım ünitesinde mortaliteyi etkileyen faktörler vazopressör tedavi ve mekanik ventilasyon ihtiyacı ve hastalık ciddiyeti olarak sıralanmıştır [2, 4]. Bu çalışmada YBÜ'de HK tanılı hastalarda klinik sonuçların ve mortaliteyi etkileyen faktörlerin araştırılması amaçlanmıştır.

\section{Gereç ve yöntem}

Bu çalışmada, Şubat 2019 ile Mart 2020 tarihleri arasında yoğun bakım takibi gerektiren 77 erişkin hastanın kayıtları geriye dönük olarak incelenmiştir. Hasta verileri tıbbi kayıtlardan toplanmıştır.

$\mathrm{Bu}$ çalışmada 3.Uluslararası Sepsis ve Septik Şok Konsensüs Tanımı (Sepsis-3) tanımı kullanıldı. Sepsis konağın enfeksiyona karşı yanıtındaki düzensizliğin neden olduğu yaşamı tehdit edici organ disfonksiyonu olarak tanımlandı. Septik şok ortalama arter basıncını $\geq 65 \mathrm{mmHg}$ düzeyinde sürdürmek için vazopresör tedavilere gereksinim duyulan inatçı hipotansiyon ve yeterli sıvı resüstasyonuna rağmen $>2 \mathrm{mmol} / \mathrm{l}$ serum laktat düzeyinin eşlik ettiği sepsis olarak tanımlandı [5]. Akut solunum yetmezliği (ARF) takipne aksesuar solunum kaslarının katılımı veya solunum kas yorgunluğu, hipoksi (<\%90), pulmoner infiltratlar ve non-invazif veya invazif mekanik ventilasyona gereksinim varlığı olarak tanımlandı [6]. Akut Solunum Sıkıntısı Sendromu (ARDS) aşağıdaki şekilde tanımlandı: solunum yetmezliğinin akut başlangıCl, göğüs filminde bilateral infiltratlar, $\mathrm{PaO} 2 / \mathrm{FiO} 2 \leq 300 \mathrm{mHg}$ olarak tanımlanan hipoksemi ve kardiyojenik ödemi dışlamak için sol atriyal hipertansiyon bulgusu olmaması veya pulmoner kapiller basınç $<18 \mathrm{mmHg}$ (ölçülmüş ise) [7]. Akut böbrek hasarı (AKI) aşağıdakilerden herhangi birinin varlığı olarak tanımlandı: 48 saat içinde serum kreatinininde $\geq 0,3 \mathrm{mg} / \mathrm{dl}$ ( $\geq 26,5$ umol/l) artış veya serum kreatinininde başlangıca göre $\geq 1,5$ kat artış (önceki 7 gün içinde olduğu bilinen veya varsayılan) veya 6 saatlik süre için idrar hacmi $<0,5 \mathrm{ml} / \mathrm{kg} / \mathrm{saat}$. Renal replasman tedavisi (RRT) sürekli veno-venöz hemofiltrasyon veya sürekli veno-venöz hemodiyaliz kullanımı olarak tanımlandı [8]. Ventilatör ilişkili pnömoni (VAP) mekanik ventilasyondan 48 saat veya daha uzun süre sonra gelişen ve yeni veya ilerleyici infiltrat, sistemik enfeksiyon bulguları (ateş, beyaz kan hücre sayısında değişim), balgam karakteristiklerinde değişim ve ajan-patojenin saptanması ile karakterize pnömoni olarak tanımlandı

Kaydedilen veriler; 1) yatış öncesinde hastalıkla ilişkili faktörler: hasta demografik özellikleri, eşlik eden hastalıklar (diyabet, kronik obstrüktif akciğer hastalığı, konjestif kalp yetmezliği, kronik böbrek hastalığı), HK tanısı, HK durumu (yeni tanı, dirençli, relaps, remisyon), yatış sırasında nötropeni, fungal pnömoni ve enfeksiyon, 2) YBÜ yatışı ile ilişkili faktörler; APACHE II skoru, solunum yetmezliği, akut solunum sıkıntısı sendromu (ARDS), alveoler hemoraji, izlemde yatışta vazopresör desteği veya mekanik ventilasyon ihtiyacı, yatıştta ve izlemde akut böbrek hasarı varlığı/ gelişimi, renal replasman tedavisi intiyacı idi. YBÜ kökenli enfeksiyon, YBÜ yatı̧ süresi ve YBÜ mortalitesi, geriye dönük olarak incelendi. $\mathrm{Bu}$ çalışma, Pamukkale Üniversitesi Tıp Fakültesi Girişimsel Olmayan Klinik Araştırma Etik Komitesi tarafından onaylandı.

\section{İstatistiksel analiz}

Veriler IBM SPSS 22.0 ile analiz edildi. YBÜ mortalitesini belirleyen prognostik değişkenler ileriye doğru basamak yöntemi kullanan ikili lojistik regresyon modeli ile gerçekleştirilen tekdeğişkenli (sürekli veriler için Mann-Whitney U ve kategorik veriler için X2) ve çok-değişkenli analizler ile değerlendirildi. $P$ değeri $<0,05$ istatistiksel olarak anlamlı kabul edildi.

\section{Bulgular}

Çalışma periyodu boyunca dahili YBÜ'ne toplam 160 hasta yatırılmıştı ve bunların 77'si (\%12) HK hastası idi. Altmış sekiz hasta Hematoloji bölümünden transfer edilirken 9 hasta acil servisten yatırılmıştı. Hastaların yaş ortalaması $56,2 \pm 15,7(20-89)$ idi ve \%62'si erkekti. 
Yatışta ortanca APACHE II skoru 25 (6-42) ve ortanca SOFA skoru 9 (4-18) idi. En sık HK'ler akut miyeloid lösemi $\% 45(n=35)$, akut lenfoid lösemi \%18,2 $(n=14)$ ve lenfoma $\% 20,8$ $(n=16)$ idi. YBÜ yatışın temel nedenleri solunum yetmezliği (62 hasta, \%80,5) olup $56 \% 72,7$ hastanın yatışında invaziv mekanik ventilasyon intiyacı mevcuttu.

Çalışmaya alınan $38 \quad(\% 50,6)$ hasta nötropenikti ve YBÜ'ne yatış sırasında 67 hastada (\%87) enfeksiyon vardı. Enfeksiyonların
\%75,3 ( $n=58)$ sağlık hizmeti ile ilişkiliydi ve hastaların \%46,8'i ( $n=36)$ septik şoktaydı.

İzlemde 58 hastada $(\% 75,3) \quad$ YBÜ enfeksiyonu gelişmişti. Yirmi dört $(\% 31,2)$ hastada bakteriyemi, $9 \quad(\% 11,7)$ hastada ventilatör ilişkili pnömoni ve $2 \quad(\% 2,6)$ hastada idrar yolu enfeksiyonu mevcuttu. YBU enfeksiyonun en sık patojenleri çokluilaç direncine sahip K.pneumoniae $(\% 14,2)$, Acinetobacter baumannii $(\% 11,6)$ ve Pseudomonas aeruginosa $(\% 5,19)$ idi (Tablo 1$)$.

Tablo 1. Hematolojik kanser tanısıyla yoğun bakım ünitesinde takip edilen hastaların demografik ve klinik özellikleri

\begin{tabular}{|c|c|c|c|}
\hline & sağ kalan & Ölen & $p$ \\
\hline Yaş, ortalama \pm (SS) & $57 \pm 16,6$ & $55,9 \pm 15,5$ & 0,77 \\
\hline Cinsiyet, Erkek (n,\%) & $16(\% 64)$ & $35(\% 67,3)$ & 0,77 \\
\hline Kanser tedavisine direnç veya relaps, $n$ (\%) & $4(\% 23,53)$ & $24(\% 58,5)$ & $0,015^{*}$ \\
\hline \multicolumn{4}{|l|}{ Hematolojik kanser tipi, n (\%) } \\
\hline Akut myeloid lösemi & $8(\% 32)$ & $27(\% 51,92)$ & 0,1 \\
\hline Akut lenfositer lösemi & $5(\% 20)$ & $9(\% 17,31)$ & 0,76 \\
\hline Kronik lenfositer lösemi & $1(\% 4)$ & $2(\% 3,9)$ & 1 \\
\hline Lenfoma & $6(\% 24)$ & $10(\% 19,23)$ & 0,63 \\
\hline Multipl myelom & $5(\% 20)$ & $4(\% 7,69)$ & 0,14 \\
\hline \multicolumn{4}{|l|}{ Komorbid Hastalıklar, n (\%) } \\
\hline Kronik obstruktif akciğer hastalığı & $1(\% 4)$ & $7(\% 13,46)$ & 0,26 \\
\hline Diabetes mellitus & $2(\% 8)$ & $6(\% 11,54)$ & 1 \\
\hline Konjestif kalp yetmezliği & $2(\% 8)$ & $5(\% 9,62)$ & 1 \\
\hline \multicolumn{4}{|l|}{ Yatışta Bulgular, n (\%) } \\
\hline APACHE II $\geq 25$ & $24(\% 96)$ & $14(\% 26,92)$ & $<0,001$ \\
\hline Akut Böbrek Yetmezliği & $7(\% 28)$ & $9(\% 17,31)$ & 0,26 \\
\hline Çoklu Organ Yetmezliği & $6(\% 24)$ & $18(\% 34,62)$ & 0,34 \\
\hline Septik şok & $1(\% 4)$ & $35(\% 67,31)$ & $<0,001$ \\
\hline Hastane Enfeksiyonu & $14(\% 56)$ & $44(\% 84,62)$ & 0,006 \\
\hline İnvaziv mekanik ventilasyon intiyacı & $4(\% 16)$ & $52(\% 100)$ & $<0,001$ \\
\hline Noninvaziv mekanik ventilasyon ihtiyacı & $4(\% 16)$ & $3(\% 5,77)$ & 0,2 \\
\hline \multicolumn{4}{|l|}{ Komplikasyonlar, n (\%) } \\
\hline Mekanik ventilatör ihtiyacı & $4(\% 16)$ & $52(\% 100)$ & $<0,001$ \\
\hline Vazoprasör tedavi intiyacı & $1(\% 4)$ & $41(\% 78,85)$ & $<0,001$ \\
\hline Ventilator ilişkili pnömoni & $0(\% 0)$ & $9(\% 17,31)$ & 0,02 \\
\hline Bakteriyemi & $5(\% 20)$ & $19(\% 36,54)$ & 0,14 \\
\hline Üriner sistem enfeksiyonu & $1(\% 4)$ & $1(\% 1,92)$ & 0,54 \\
\hline Akut böbrek Yetmezliği & $5(\% 20)$ & $18(\% 34,62)$ & 0,18 \\
\hline Hemodiyaliz tedavi intiyacı & $6(\% 24)$ & $20(\% 38,46)$ & 0,2 \\
\hline \multicolumn{4}{|l|}{ Kültürde üreme sonuçları, n (\%) } \\
\hline Acinetobacter baumannii, & $1(\% 4)$ & $8(\% 15,38)$ & 0,25 \\
\hline Klebsiella pneumoniae & $3(\% 12)$ & $8(\% 15,38)$ & 1 \\
\hline Escherichia coli & $2(\% 8)$ & $5(\% 9,62)$ & 1 \\
\hline Pseudomonas aureginosa & $1(\% 4)$ & $3(\% 5,77)$ & 1 \\
\hline Enterecoccus spp, & $0(\% 0)$ & $9(\% 17,31)$ & 0,02 \\
\hline Yoğun bakım yatış süresi, Ortanca (min-max) & $2(1-12)$ & $3,5(1-39)$ & 0,12 \\
\hline Hastane yatış süresi, Ortanca (min-max) & $2(1-12)$ & $3,5(1-39)$ & 0,12 \\
\hline
\end{tabular}


Ortalama YBÜ yatış süresi $5,7 \pm 6,5$ gündü. Genel YBÜ sağ kalım oranı \%32,5 (25 hasta) idi. APACHE II skoru $\geq 25$ olan 39 hastadan sadece biri sağ kaldı (\%4). Ölüme dek geçen ortanca süre 3 (1-39) gündü. Tek değişkenli analizde yoğun bakıma kabulde mortaliteyi etkilediği ön görülen değişkenler; APACHE II skoru $\geq 25(p<0,001)$, kanser tedavisine direnç veya relaps $(p=0,015)$, yatışta septik şok $(p<0,001)$, invaziv mekanik ventilasyon ihtiyacı $(p<0,001)$ ve hastane enfeksiyon varlığı $(p=0,006)$ istatistiksel olarak anlamlı risk faktörleri olarak saptandı (Tablo 1). Bu değişkenler ile kurulan çok değişkenli model sonucunda ise APACHE II yüksekliğinin istatistiksel olarak anlamlı risk faktörü (OR:1,268; \%95 C.I:1,111-1,447) ve mortalite için anlamlı bir tahmin edici olduğu görüldü (ROC:0,884) (Tablo 2) (Şekil 1).

Tablo 2. Hematolojik kanser tanısıyla yoğun bakım ünitesinde takip edilen hastaların mortalite risk faktörlerinin lojistik regresyon analizi

\begin{tabular}{lllll}
\hline & Odds & \%95 Güven & \%95 Güven & \\
& Oranı & Aralığı, Alt Limit & Aralığı, Üst Limit & $p$ \\
\hline APACHE II & 1,268 & 1,111 & 1,447 & $<0,001$ \\
Hastane enfeksiyonu olması & 0,594 & 0,050 & 7,019 & 0,679 \\
Kanser tedavisine yanıtsızlık & 0,457 & 0,077 & 2,730 & 0,391 \\
\hline
\end{tabular}

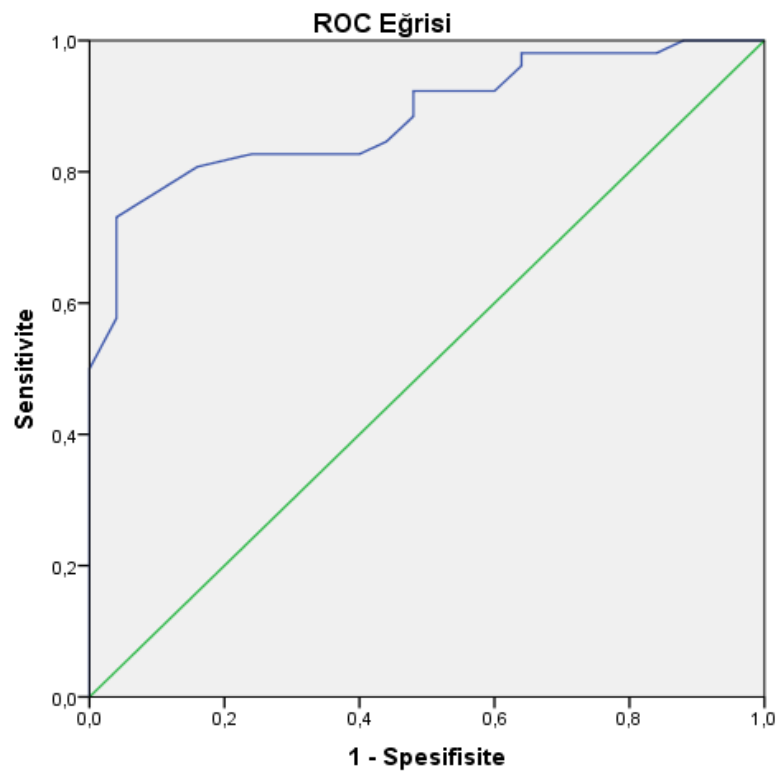

Şekil 1. APACHE 2 ROC eğrisi

\section{Tartışma}

$\mathrm{Bu}$ çalışmada, HK hastalarının genel YBÜ sağ kalım oranları \%32,5 literatürde bildirilenlerden düşüktü [4, 9-11]. APACHE skoru $\geq 25$, septik şok ve yatışta hastane kökenli enfeksiyon varlığı YBÜ mortalitesini öngördü ve APACHE II skoru $\geq 25$ olumsuz sonuç için güçlü bir göstergeydi (ROC:0,884).

Avustralya'da yoğun bakım ünitesindeki 113 HK hastası incelendiği bir çalışmada 30-günlük sağ kalım oranı \%63 iken 1-yıllık sağ kalım oranı \%4,7 olarak bildirilmiştir [10]. Kısa dönem sağ kalımın APACHE II skoru, altta yatan sepsis ve YBÜ'ne yatış anında organ yetmezliklerinin sayısına bağlı olduğu gösterilmiştir. Uzun dönem sağ kalım sonuçlarını ise altta yatan malignite etkilemektedir. HK hastalarının incelendiği bir başka çalışmada; \%70'inin YBÜ'de sağ kaldığını ve YBÜ'de ölen hastalara kıyasla YBÜ'de sağ kalan hastaların anlamlı şekilde daha düşük APACHE II ve SOFA skorları ve YBÜ'ne yatışta daha az sayıda organ sistem yetmezliği ile karakterize olduğu gösterilmiştir [11].

Tüm Dünya'da ve ülkemizde Hematolojik kanser (HK) tanısı alan hastaların sayısı 
artmakla birlikte son dönem geliştirilen tanı, anti-neoplastik tedaviler ve destekleyici tedaviler sayesinde, bu hastaların tedavi başarısı artmakta ve yaşam süreleri uzayan bu hastalar kanserle ilişkili konular ve agresif kemoteröpatik komplikasyonları nedeniyle YBÜ desteğine gereksinim duyar. Hematolojik malignensi bulunan hastaların YBÜ'ne transferinin uygun şekilde yapılarak maliyet etkin yoğun bakım ünitesi ve kaynak kullanımına ilişkin kılavuzlar mevcuttur [11, 12]. Son evre ve palyatif evredeki malignite hastalarının YBÜ'ne transferi önerilmez. Ancak günümüzde bu kriterler tartışmalıdır. Son yıllarda, 3-5 gün süre ile sınırsız destekle birlikte daha geniş YBÜ yatış kriterleri daha sık önerilmektedir. 5 günden sonra, özellikle organ yetmezliği çözülmemişse ve hasta mekanik ventilasyon ve noradrenaline gereksinim duyuyorsa YBÜ genellikle YBÜ desteğinin sınırlanması önerilir çünkü bu hastalar kötü prognoza sahiptir [5]. Bir çalışmada, 3.günden sonra entübasyon, vazopresör veya diyalize gereksinim duyan tüm hastaların mortal seyrettiği bildirilmiştir. 5.gün sağ kalanlarda hastane sağ kalımı \%40 ve genel sağ kalım \%21 olması nedeniyle 5.günden sonra tedavinin sınırlanması önerilmiştir [12]. Bir başka çalışmada YBÜ yatışı sırasında artan SOFA skoru ve mortalite arasında güçlü bir ilişki bildirilmiş ve YBÜ yatışı sırasında SOFA skorundaki değişikliklerin izlenmesinin tedavi devamı konusunda yardımcı olabileceği vurgulanmıştır [13]. Çalışmamızda, yoğun bakımda izlediğimiz hastalarda herhangi bir triaj kriteri uygulanmamıştır ve tüm hastalar tam destek ile YBÜ'ne kabul edilmişti. Ayrıca hastaların izlemi sırasında herhangi bir tedavi sınırlandırma protokolü uygulanmamıştır. Bu çalışma ile APACHE II skoru $\geq 25$ olan hastaların kötü prognoza sahip olduğu ve bu skorun YBÜ'de mortalite prognozu için iyi bir gösterge olabileceği gösterilmiştir.

Sepsis ve solunum yetmezliği YBÜ yatışının sık endikasyonlarıdır ve sıklıkla olumsuz sonuçla birliktedir [4, 10, 12, 14-16]. Çalışmamızda 67 hastada (\%87) enfeksiyon vardı. Enfeksiyonların $\% 75,3 \quad(n=58)$ sağlık hizmeti ile ilişkiliydi ve $\% 46,8(n=36)$ septik şokla ilişkiliydi. Septik şok mortalite için önemli bir risk faktörüydü.

Mortalite ile ilişkili diğer bir önemli risk faktörü ise solunum yetmezliğidir. Çalışmamızda, YBÜ yatışın temel nedenleri solunum yetmezliği (62 hasta, \%80,5) olup 56 hastanın (\%72,7) mekanik ventilasyon intiyacı olmuştu. Bird ve ark. [4] çalışmasında özelleşmiş bir kanser YBÜ'deki 199 HK hastası mortalite açısından incelenmiştir. Düşük YBÜ mortalite (\%34) oranları bildiilmiştir ve sadece çoklu-organ yetmezliği ve invazif mekanik ventilasyon mortalitenin anlamlı prediktörü olarak bildirilmiştir [4]. Ancak bu çalışmada; olumsuz prediktörlere (ikinci sıra tedavi/hastalık relapsı/refrakter hastalık ve hızlı hastalık progresyonu/kötü fonksiyonel durum/ şiddetl komorbid durumlar) sahip hastalar YBÜ'ne alınmamıştır.

Kemoteröpatik ajanlara bağlı immünsupresyon ve altta yatan hastalık nedeniyle HK hastaları hastane kaynaklı enfeksiyonlar için yüksek risk altındadır [17]. Hastane kaynaklı pnömoni, özellikle de fungal pnömoni, ve bakteriyemi HK hastalarında önde gelen hastane kaynaklı enfeksiyonlardır. Fungal pnömoni görülme sıklığı genellikle hastane çevresi ve altta yatan malignansi ile ilişkilidir [18]. Çalışmamızda 58 hastada $(\% 75,3)$ YBÜ enfeksiyonu en sık $24(\% 31,2)$ bakteriyemi, 9 $(\% 11,7)$ ventilatör ilişkili pnömoni ve $2(\% 2,6)$ idrar yolu enfeksiyonu vardı ve çoklu-ilaç direncine sahip K.pneumoniae, Acinetobacter baumannii ve Pseudomonas aeruginosa en sık patojenlerdi. Bakteriyemi mukozal hasar nedeniyle genellikle endojen floradan köken alır. Bununla birlikte, santral venöz kateterlerin artan kullanımı HK hastalarında bakteriyemi için bir başka risk faktörüdür [18]. MDR patojenler YBÜ'de HK hastaları için büyük risk taşır ve sonuç üzerinde olumsuz etkiye sahiptir [19]. Çalışmamızda bakteriyemi en sık YBÜ enfeksiyonuydu ve tüm patojenler çoklu ilaç direncine sahipti. Diğer yandan, hastaların \%29'u karbapenem dirençli K.pneumoniae veya VRE ile kolonize olmuştu.

Retrospektif, tek-merkezli bir çalışma olması nedeniyle YBÜ desteği ve YBÜ enfeksiyonlarına ilişkin bazı eksik veriler bu çalışmanın en önemli kısıtlılığıdır. Bir diğer kısıtlılık ise, risk faktörleri için güven aralıkları sağ kalan gruptaki hasta sayısının azlığı nedeniyle oldukça geniş olmasıdır. Bu durum örneklem büyütülerek önlenebilir ve bulgularımızı doğrulamak için çok-merkezli çalışmalara gereksinim vardır.

Sonuç olarak, APACHE II skoru $\geq 25$ ve septik şok önemli kötü prognoz kriterleridir. Kemoteröpatik ajanlara bağlı immünsupresyon 
ve altta yatan hastalık nedeniyle HK hastaları hastane kaynaklı enfeksiyonlar için yüksek risk altında olduğundan bu hastalarda hastane enfeksiyonlarının önlenmesi de kritik öneme sahiptir. Tüm Dünya'da ve ülkemizde yoğun bakım intiyacı olan HK hastalarının sayılarının artması nedeniyle takip ve tedavisinde belirlenecek protokoller, destekleyici tedaviler ile tedavi başarısının ve yaşam süresinin uzatılması sağlanabilir.

Çıkar ilişkisi: Yazar çıkar ilişkisi olmadığını beyan eder.

\section{Kaynaklar}

1. Vijenthira A, Chiu N, Jacobson D, et al. Predictors of intensive care unit admission in patients with hematologic malignancy. Sci Rep 2020;10:21145. https://doi.org/10.1038/s41598-020-78114-7

2. Cornish M, Butler MB, Green RS. Predictors of poor outcomes in critically III adults with hematologic malignancy. Can Respir J 2016;2016:9431385. https:// doi.org/10.1155/2016/9431385

3. Hill QA, Kelly RJ, Patalappa C, et al. Survival of patients with hematological malignancy admitted to the intensive care unit: prognostic factors and outcome compared to unselected medical intensive care unit admissions, a parallel group study. Leuk Lymphoma 2012;53:282-288. https://doi.org/10.3109/10428194.2 011.614705

4. Bird GT, Farquhar Smith P, Wigmore T, Potter M, Gruber PC. Outcomes and prognostic factors in patients with haematological malignancy admitted to a specialist cancer intensive care unit: a $5 \mathrm{yr}$ study. $\mathrm{Br} \mathrm{J}$ Anaesth 2012;108:452-459. https://doi.org/10.1093/bja/aer449

5. Singer M, Deutschman CS, Seymour CW, et al. The third international consensus definitions for sepsis and septic shock (Sepsis-3). JAMA 2016;315:801-810. https://doi.org/10.1001/jama.2016.0287

6. Yoo H, Suh GY, Jeong BH, et al. Etiologies, diagnostic strategies, and outcomes of diffuse pulmonary infiltrates causing acute respiratory failure in cancer patients: a retrospective observational study. Crit Care 2013;17:150. https://doi.org/10.1186/cc12829

7. ARDS Definition Task Force, Ranieri VM, Rubenfeld GD, Thompson BT, et al. Acute respiratory distress syndrome: the Berlin Definition. JAMA. 2012;307:25262533. https://doi.org/10.1001/jama.2012.5669

8. Khwaja A. KDIGO clinical practice guidelines for acute kidney injury. Nephron Clin Pract 2012;120:179-184. https://doi.org/10.1159/000339789
9. Escobar K, Rojas P, Ernst D, et al. Admission of hematopoietic cell transplantation patients to the intensive care unit at the Pontificia Universidad Católica de Chile Hospital. Biol Blood Marrow Transplant 2015;21:176-179. https://doi.org/10.1016/j. bbmt.2014.08.009

10. Parakh S, Piggin A, Neeman T, Mitchell I, Crispin P, Davis A. Outcomes of haematology/oncology patients admitted to intensive care unit at The Canberra Hospital. Intern Med J 2014;44:1087-1094. https://doi. org/10.1111/imj. 12545

11. McGrath S, Chatterjee F, Whiteley C, Ostermann M. ICU and 6-month outcome of oncology patients in the intensive care unit. QJM 2010;103:397-403. https://doi. org/10.1093/qjmed/hcq032

12. Lecuyer L, Chevret S, Thiery G, Darmon M, Schlemmer B, Azoulay E. The ICU trial: a new admission policy for cancer patients requiring mechanical ventilation. Crit Care Med 2007;35:808-814. https://doi.org/10.1097/01. CCM.0000256846.27192.7A

13. Geerse DA, Span LF, Pinto Sietsma SJ, van Mook WN. Prognosis of patients with haematological malignancies admitted to the intensive care unit: Sequential Organ Failure Assessment (SOFA) trend is a powerful predictor of mortality. Eur J Intern Med 2011;22:57-61. https://doi.org/10.1016/j.ejim.2010.11.003

14. Aygencel G, Turkoglu M, Turkoz Sucak G, Benekli M. Prognostic factors in critically ill cancer patients admitted to the intensive care unit. J Crit Care 2014;29:618-626. https://doi.org/10.1016/j.jcrc.2014.01.014

15. McGrath S, Chatterjee F, Whiteley C, Ostermann M. ICU and 6-month outcome of oncology patients in the intensive care unit. QJM. 2010;103:397-403. https:// doi.org/10.1093/qjmed/hcq032

16. Malak S, Sotto JJ, Ceccaldi J, et al. Ethical and clinical aspects of intensive care unit admission in patients with hematological malignancies: guidelines of the ethics commission of the French society of hematology. Adv Hematol 2014;2014:704318. https:// doi.org/10.1155/2014/704318

17. Thom KA, Kleinberg M, Roghmann MC. Infection prevention in the cancer center. Clin Infect Dis 2013;57:579-585. https://doi.org/10.1093/cid/cit290

18. Huoi $C$, Vanhems $P$, Nicolle $M C$, Michallet $M$, Bénet $\mathrm{T}$. Incidence of hospital-acquired pneumonia, bacteraemia and urinary tract infections in patients with haematological malignancies, 2004-2010: a surveillance-based study. PLoS One. 2013;8:e58121. https://doi.org/10.1371/journal.pone.0058121

19. Cornejo Juárez P, Vilar Compte D, Pérez Jiménez C, Ñamendys Silva SA, Sandoval Hernández S, Volkow Fernández P. The impact of hospital-acquired infections with multidrug-resistant bacteria in an oncology intensive care unit. Int J Infect Dis 2015;31:31-34. https://doi.org/10.1016/j.ijid.2014.12.022 
Etik kurul onayı: Pamukkale Üniversitesi Tıp Fakültesi Girişimsel Olmayan Klinik Araştırma Etik Komitesi tarafından 03/03/2020 tarih ve 05 sayı ile onaylanmıştır.

\section{Yazarların makaleye olan katkıları}

İ.H.A. makalenin konseptini hazırlamıştır. İ.H.A. tarafından literatür taraması ve edinilen bilgilerin yorumlanması yapılmıştır. Makale I.H.A. tarafından yazılmıştır. İ.H.A. gözden geçirip gerekli düzeltmeleri yapmıştır. Makalenin tamamını tartışmış ve son halini onaylamıştır. 